\title{
The measurement series foreword
}

\section{STRATEGIC MANAGEMENT AND ENTREPRENEURSHIP AS FIELDS OF STUDY}

Strategic management and entrepreneurship are both relatively new fields of study. Both are, therefore, experiencing the myriad pains associated with 'growth', including issues related to the legitimacy and definitions of the fields themselves, as well as to the development of new knowledge regarding the various phenomena that they address.

Currently, both fields are healthy and vibrant - a fact substantiated by several indices, including: (i) an increasing number of articles and books being published in both fields; (ii) increasing professional meeting program time being devoted to papers, symposia and workshops addressing the issues of each field; (iii) an increasing number of scholars indicating both fields as the primary focus of their teaching and research; (iv) an increasing number of graduate students seeking $\mathrm{PhDs}$ in both fields; and (v) an increasing number of universities offering PhD programs in one or both of these fields.

In the 1970s, the field of strategic management was beginning to evolve as an academic discipline from the business policy and planning area, which had existed at most business schools as a 'capstone' course for their MBA and executive program curricula. Toward the end of that decade, I helped Dr Dan Schendel, currently the editor of the Strategic Management Journal, to organize a conference at the University of Pittsburgh around the theme 'Strategic Management: A New View of Business Policy and Planning'. Later, Dan and I published a Proceedings of that Conference under this title. In addition, we co-edited a series of 'advanced' strategic management texts, with the help of Richard Feldman of West Publishing Company, which addressed various important issues in this newly emerging field.

At that time, one of the major 'challenges' facing the fields of both strategic management and entrepreneurship, in the opinion of many of the scholars in them, was the lack of a substantial theoretical base for these fields. As a consequence, most of the research that was done in both fields at that time was of an exploratory nature. The major focus was on trying to describe the phenomenon of interest, and trying to abstract from 'best 
industry practices' some 'guidelines for success' that we might pass on to our students in the classroom.

Today, the creation of a theoretical base is no longer the key issue facing the fields of strategic management and entrepreneurship. In fact, if anything, there are almost too many theories and theoretical articles being developed with too little empirical research being done to support the various theoretical speculations that are being made by the scholars in both fields.

There is broad recognition of this problem, with frequent calls for more 'theory-based' research in both fields. However, what is lacking is not a theoretical base for doing such research, it is effective 'measures' of many, if not most, of the basic concepts that are key components of these theories.

I have had the honor and privilege of serving as the liaison between the Academy of Management's Entrepreneurship Division and the individuals and organizations that have sponsored the Heizer Award for Outstanding Research in New Enterprise Development for the past 30 years, and the Division and the National Federation of Independent Business (NFIB) Foundation Award for Outstanding Research in Entrepreneurship and Independent Business for the past 15 years. In addition, during the 1970s and early 1980s, I served as liaison between the Academy's Business Policy and Strategy Division and the General Electric Company when it sponsored the GE Award for Outstanding Research in Strategic Management and the A.T. Kearney Company when it sponsored the A.T. Kearney Award for Outstanding Research in General Management. In these roles, I had the opportunity to receive and read some of the leading dissertations done in the fields of entrepreneurship and strategic management over the past three decades.

The major trend that is immediately obvious when one examines these dissertations is increasing amounts of very high-quality doctoral research in both fields. Three other trends are also apparent, however: (i) increasing attention to the development of hypotheses and propositions based on various theories (that is, to theory-based research) in both fields; (ii) increasing sample sizes in most of the more recent dissertations; and (iii) less attention to and/or 'critical' discussion of the appropriate measures for the concepts that make up these hypotheses and propositions. Regrettably, this relative lack of attention to 'measurement issues' is one of the factors most responsible for the lack of greater progress in both fields.

\section{THE IMPORTANCE OF MEASUREMENT}

The importance of measurement is summed up by J.P. Peter in the Journal of Marketing Research (1979: 6), as follows: 
Valid measurement is the sine qua non of science. In a general sense, validity refers to the degree to which instruments truly measure the constructs which they are intended to measure. If the measures used in a discipline have not been demonstrated to have a high degree of validity, that discipline is not a science.

There is little dispute among scholars that the purpose of most research in business is to provide a greater understanding of how the decisions made by managers impact organizational performance.

Unfortunately, even though scholars in most fields of business increasingly agree that shareholder wealth creation is the best measure of overall performance, none of the traditional measures of financial performance correlates with shareholder value creation strongly enough that it could be used as a surrogate for shareholder value creation. This is clearly problematic for the field.

A recent review of the Academy of Management Journal, the Strategic Management Journal, the Journal of Management, the Journal of Business Venturing and Entrepreneurship Theory and Practice revealed that the 138 research studies published between July 1996 and June 21 that assessed overall organizational performance used 133 different measures of that construct. In short, there are currently no 'generally accepted' measures of overall organizational performance that can be used across studies to help advance our knowledge base in either strategic management or entrepreneurship.

In addition, a similar review of research studies published between 1996 and 2001 in the Academy of Management Journal, the Strategic Management Journal, the Journal of Management, the Journal of Business Venturing and Entrepreneurship Theory and Practice that used the concept of organizational strategy as one of the study's independent variables revealed that none of these studies' authors measured that concept in precisely the same way. Furthermore, almost all of them used single-attribute indices to measure organizational strategy even though most major strategic management scholars 'define' strategy as a multi-attribute concept. The net result is that none of these studies' findings regarding organizational strategy has built on prior research findings regarding such strategy in a way that would allow one to develop a general set of conclusions regarding the influence of organizational strategy on the performance of the organizations studied.

In other words, there are major 'measurement' problems in both strategic management and entrepreneurship because there are currently no 'generally accepted' 'measures' for several of the major concepts of both fields, including 'overall organizational performance', 'organizational strategy', 'top management and/or entrepreneurial teams', 'organizational resources' and 'environmental opportunities'. 
The major purpose of the Edward Elgar 'Measurement Series' is to address some of these measurement issues in the fields of strategic management and entrepreneurship.

\section{THE ORIGIN OF THE MEASUREMENT SERIES}

The origin of the Measurement Series lies in a series of $10 \mathrm{PhD}$ dissertations done at the University of Georgia's Terry College of Business under the supervision of Dr Charles W. Hofer over a period of 20 years that won a total of 12 dissertation awards in the field of entrepreneurship during this period, that is, about 25 percent of all of the dissertation awards given in this field over this period of time.

The purpose of the initial dissertations done under Hofer's supervision was to try to identify the 'determinants of new venture performance' and these dissertations utilized a number of concepts from the field of strategic management to address this issue. Very early, however, it became clear that there were a number of 'measurement' issues that had to be addressed to do this research effectively. Consequently, each new dissertation in the series was designed to explicitly address one or more of these measurement issues. Figure 1 lists the dissertations in the series, and notes some of the key issues addressed by each dissertation.

The two most important factors from the perspective of potential users of the materials contained in the Measurement Series are

1. The fact that most of the measurement concepts and methods that will be covered in the series have been used, tested and refined in these 'awardwinning' dissertations using relatively large-scale databases using data covering both robust and non-robust periods of economic activity.

2. The fact that the judges for these various dissertation awards included the most senior and respected scholars in the world in the field of entrepreneurship, that is: Raphael Amit, Candy Brush, Bill Bygrave, Arnold Cooper, Tom Dean, William Gartner, Robert Hishrich, Jerry Katz, Ian MacMillan, Patricia McDougall, Ron Mitchell, Paul Reynolds, Harry Sapienza, Kelly Shaver, Dean Sheppard, Howard Stevenson, Jeff Timmons, Nancy Upton, V. Venkatraman, Karl Vesper, Harold Welch and Shaker Zhara.

The bottom line is that the measurement concepts and methods that will be covered in the Measurement Series have been reviewed and deemed to be among the 'best' in the world by a set of judges consisting of the best scholars in the world in the field of entrepreneurship. 


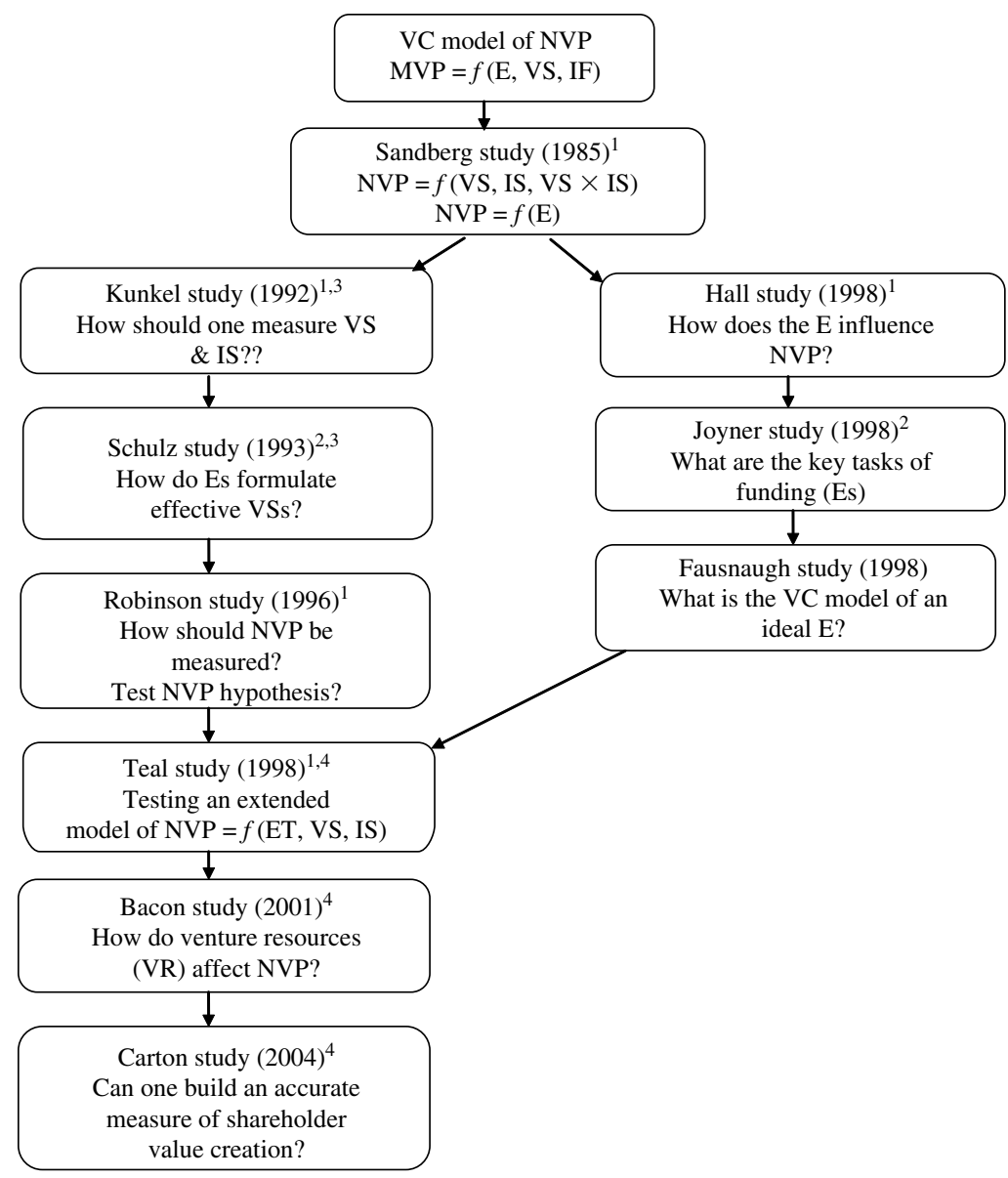

Notes:

1. Won a Heizer Award (5).

2. Won an NFIB Award (2).

3. Won a TIMS/ORSA Award (2).

4. Won a Carland Award (3).

Figure 1 Research on the determinants of new venture performance

\section{THE MEASUREMENT SERIES}

The Measurement Series will focus on 'measurement issues' associated with research in the fields of strategic management and entrepreneurship. Each book in the series will review the measurement issues associated with the 
topic(s) they cover, and then present one or more innovative model(s) for addressing these measurement issues. Each book will also provide questionnaires, data classification forms and discussions of how to use them.

The Measurement Series will begin with two books - one on the 'measurement of organizational performance' and one on the 'measurement of organizational strategy'.

Carton and Hofer's book, Measuring Organizational Performance, develops two new multi-attribute models for 'measuring' shareholder wealth creation - one covering one-year timeframes and the other covering three-year time periods. The accuracy and effectiveness of both measures was tested on largescale databases. Particular attention was paid to the ability of the measures to identify and differentiate between high- and low-performing firms, since the 'essence' of both strategic management and entrepreneurship is the development of new knowledge for improving overall organizational performance. Both measurement models correlated with shareholder value creation in high- and low-performing firms with an $R^{2}$ of over 0.60 , a 500 percent improvement over the 'best' of the measures used in the myriad research studies conducted in both fields over the past decade. Moreover, both new organizational performance measures use only accounting data, so they can be used as proxies for measuring increases in shareholder value for both publicly and privately held firms, including small and family businesses.

Hofer's book, Measuring Organizational Strategy, reviews the various metrics that have been used to measure strategy over the past two decades, and then develops two multi-attribute strategy measurement models, one to measure business-level strategy and one to measure corporate-level strategy. Hofer's business-level strategy measurement model has been used in four $\mathrm{PhD}$ dissertations that have won six awards for outstanding research in the field of entrepreneurship, while his corporate-level strategy measurement model is the first major extension of Richard P. Rumelt's corporate strategy classification system put forward in the past 30 years.

Two further books covering the 'measurement of top management (or founding entrepreneurial) teams' and the 'measurement of organizational resources' are planned after the initial books are completed. In addition, books on the 'measurement of environmental opportunities' and 'content analysis in strategic management and entrepreneurship' are under consideration. 